\title{
Mechanical Behavior of Corroded Protruding Rebars From Unfinished Concrete Structures
}

\author{
Drakakaki Arg', Diamantogiannis $\mathbf{G}^{1}$, Apostolopoulos $\mathrm{Ch}^{1 *}$ and Apostolopoulos Alk \\ 1 University of Patras, Panepistimioupoli Patron 265 04, Greece \\ ${ }^{2}$ University of loannina, Epirus, Greece
}

\begin{abstract}
In the current study, the effects of chloride-induced corrosion on B500c semi-embedded steel bars, both immersed in a salt-spray chamber and on protruding areas of existing structures, are evaluated in terms of mass loss and mechanical characteristics. Comparison of corrosion damage rates between bare and semi-embedded specimens at the early stages of the corrosion test, indicates that the bare steel bars present quite high mass losses, which however, over exposure time reach approximately similar rates to the ones presented by the semi-embedded steel bars. As far as mechanical characteristics are concerned, the mass loss of semi-embedded steel rebars, at the protruding site, is related to the strength and ductility properties drop. At the same time, while the corrosion exposure time is increasing in bare samples, a continuous-almost linear and proportional to the mass loss-reduction of the strength properties and the uniform elongation is observed. Finally, a worth referring point is the appearance of two Ludder areas on stress-strain diagrams of semi-embedded steel bars, a point that confirms the different corrosion mechanism of protruding areas in comparison to the bare or the wholly embedded ones.
\end{abstract}

Keywords: Mechanical behavior; Semi-embedded steel bars; Rebars

\section{Introduction}

As it is widely known, the protruding rebar consist steel bars emerging from the structural components (columns and beams) intended for future use and more specifically for further extension of the frames of reinforced concrete structures. In certain Mediterranean countries, such as Greece or Turkey, it is quite often for the protruding rebar to be left without any protection. This fact, however, often raises speculations concerning the structural integrity of steel, mainly due to the corrosive environmental action.

According to Figure 1, region A consists the rebar part which is emerging from the concrete and since it is bare, inevidably it is exposed to the corroding environment of the atmosphere. The regulatory framework concerning the rebars of region $\mathrm{A}$, is conducted by ISO 12944 [1]. According to ISO 12944 [1], the corrosiveness is directly related to the environmental exposure category, the type of polluting compounds such as $\mathrm{SO}_{4}{ }^{2-}, \mathrm{NO}_{2}, \mathrm{Cl}^{-}$and other gas phase compounds like $\mathrm{H}_{2} \mathrm{~S}, \mathrm{CO}_{2}$, etc. An important parameter on the mechanism of atmospheric corrosion also consists the percentage of relative humidity on the steel surface. In terms of regulatory framework, region B which consists the protruding part of the steel reinforcement bars, is conducted according to EN 206-1 [2] with the reference that concrete thickness, which is coating the steel, is defined zero. The contact of free concrete surface with the atmospheric pollution, as well as the given

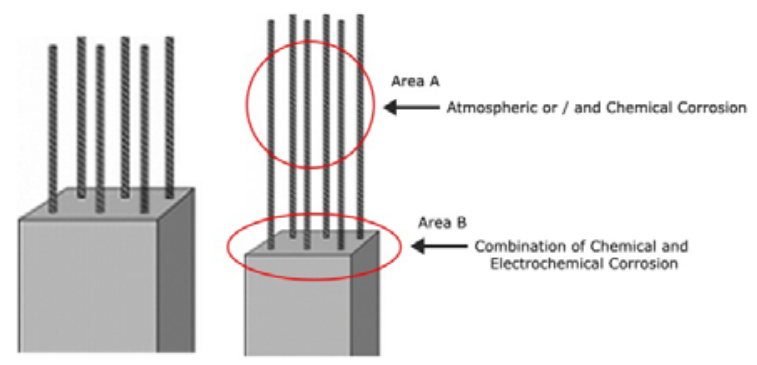

Figure 1: Typical representation of steel protrudongrebars and discrimination of two regions $A$ and $B$. penetration of the water into the concrete, makes region B particularly complex. This complexity is directly related to the interaction between chemical and electrochemical corrosion or just with corrosion using atmosphere and polluting deposits as electrolytes or even concrete. Also, a quite important percentage of steel corrosion (region B), may happens due to microbiological induced corrosion (MIC) $[3,4]$ derived from the animal (exudates of microorganisms) and the natural environment (aureobasidium pullulans-cladosporium cladosporioides -alternaria alternata etc)

In existing structures, at steel bar protruding sites, can be quite often noticed an increased corrosion rate and as a result a significant decrease of sectional area, which comes in contrast with low decrement of sectional areas which appeared in bare rebars.

This is the reason why the seismic vulnerability of existing reinforced concrete (RC) buildings in coastal areas should be determined with reliability, even in an approximate manner, using the extent of reinforcement corrosion in the structural elements).

Browsing in the literature, on topics such as the mechanical behavior of steel bars due to corrosion, several studies came of concerning both bare and embedded steel bars. There comes a conclusion, that corrosion causes a reduction in mass of the rebar reinforcement and a change in the mechanical characteristics of the steel (strength and ductility properties) $[5,6]$.

Additionally, Apostolopoulos et al. [7,8] has proved through extended studies that the corrosive action localized on the constructions,

*Corresponding author: Apostolopoulos Ch, University of Patras, Panepistimioupol Patron 265 04, Greece, Tel: +30-26510-05772; E-mail: charrisa@mech.upatras.gr

Received February 05, 2014; Accepted April 27, 2015; Published May 05, 2015

Citation: Drakakaki Arg, Diamantogiannis G, Apostolopoulos $\mathrm{CH}$, Apostolopoulos Alk (2015) Mechanical Behavior of Corroded Protruding Rebars From Unfinished Concrete Structures. J Appl Mech Eng 4: 165. doi:10.4172/2168-9873.1000165

Copyright: (c) 2015 Drakakaki Arg, et al. This is an open-access article distributed under the terms of the Creative Commons Attribution License, which permits unrestricted use, distribution, and reproduction in any medium, provided the original author and source are credited. 
is time dependent and is associated with the type of concrete and reinforcement used and the intensity of environmental exposure to penetrating chlorides.

The initiation and rate of increase of reinforcement corrosion and the parameters that influence corrosion have been described using physicochemical models that take into account the material composition and the geometric characteristics of the RC elements [9].

Several investigations have been published in the literature on the evaluation of the chloride corrosion damage, as well as, the mechanical behavior of steel reinforcing bars.

However, the extent and the consequences of the induced corrosion damage on the protruding steel bars have not been studied to a similar range [10].

The induced damage on the protruding part is associated with a micro crack network development in concrete and thus should be expected to influence the rate of chloride ingress and more aggressive agents as well. The protruding area (concrete- steel) is considered to be a critical region for a future development of a frame structure, however, a little attention is paid to structural preparation and much more is paid on the valuation of the mechanical behavior of exposed steel bars.

To approach the mechanical behavior valuation of protruding found in existing structures, primarily loss measurements concerning the sectional areas of protruding steel bars were demanded. Semiembedded bars, after a process of tensile tests, were compared to reference samples and they were experimentally simulated using laboratory corrosion.

\section{Measurements in Existing Structures}

There took place local measurements of sectional area loss which corresponds to mass loss of protruding steel bars of existing structures, which were categorized to exposure levels $\mathrm{XS}_{2}$ and $\mathrm{XS}_{3}$ according to EN 206 standard [2]. Particularly, these are the pedestals of a bridge located an Ionian Street, in place Gavrolimnis, as shown in Figure 2, (near the famous Rio- Antirrio bridge). This structure as well as many others located to the network of Highway of Greece has remained unfinished, because of economic hardship, for the last two years.

Measurements were performed in numerous protruding steel bars exposed to environmental conditions. Exposure rules concerning the bare parts of protruding steel bars are conducted according to ISO 12944 [1] and they enlist the test to the C5-M category, which is characterized by high or very high corrosion rates, which means about $50 \mu \mathrm{m} / 200 \mu \mathrm{m} /$ per year.

On the contrary, the examination of the embedded part of the protruding bars is taking place according to European Standard EN206-1 [2] and is enlisted to $\mathrm{XS}_{2}$ and $\mathrm{XS}_{3}$ categories (Table 1).

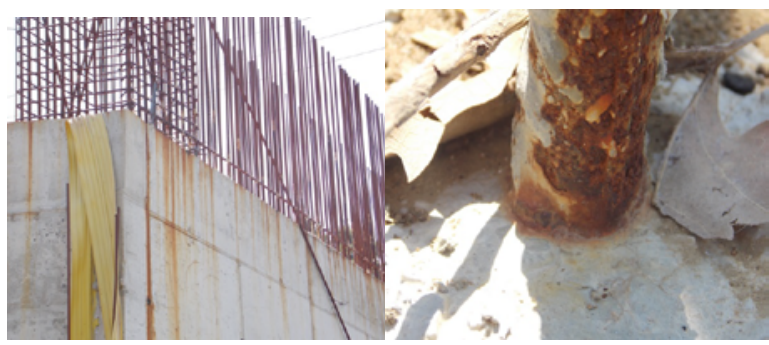

Figure 2: View of existing pedestals and of a typical protruding.

\begin{tabular}{|c|c|}
\hline $\begin{array}{c}\text { Classification of region A } \\
\text { according to ISO 12944 standard }\end{array}$ & $\begin{array}{c}\text { Classification of region B according to } \\
\text { EN 206-1 standard }\end{array}$ \\
\hline C2 & XA1 \\
\hline C3 & XC3,XC4,XA2 \\
\hline C4 & XD1, XA2, XC3,XC4 \\
\hline C5-1 & XC3,XC4,XA2,XA3 \\
\hline C5-M & $\mathrm{XC3}, \mathrm{XC4}, \mathrm{XS} 2, \mathrm{XS} 3, \mathrm{XA} 2, \mathrm{XA} 3$ \\
\hline
\end{tabular}

Table 1: Environmental classification of protruding steel bars according to specific standards.

\begin{tabular}{|l|l|l|l|l|l|l|l|l|l|}
\hline $\begin{array}{l}\text { Steel } \\
\text { bar 1 }\end{array}$ & $\begin{array}{l}\text { Steel } \\
\text { bar 2 }\end{array}$ & $\begin{array}{l}\text { Steel } \\
\text { bar 3 }\end{array}$ & $\begin{array}{l}\text { Steel } \\
\text { bar 4 }\end{array}$ & $\begin{array}{l}\text { Steel } \\
\text { bar 5 }\end{array}$ & $\begin{array}{l}\text { Steel } \\
\text { bar 6 }\end{array}$ & $\begin{array}{l}\text { Steel } \\
\text { bar 7 }\end{array}$ & $\begin{array}{l}\text { Steel } \\
\text { bar 8 }\end{array}$ & $\begin{array}{l}\text { Steel } \\
\text { bar 9 }\end{array}$ & $\begin{array}{l}\text { Steel } \\
\text { bar 10 }\end{array}$ \\
\hline 17.40 & 17.55 & 17.67 & 17.41 & 17.12 & 17.29 & 17.34 & 17.2 & 17.24 & 17.63 \\
\hline
\end{tabular}

To calculate the remaining sectional area corresponding to mass loss on specific heights of the bar, two diameter measurements were taken in two perpendicular directions. The final diameter was calculated as the average of these measurements. Before this procedure, a local cleaning was performed according to ASTM G1 standard [11].

Table 2 presents the results of the average diameter, referred to the free (bare) region $\mathrm{A}$, of 10 protruding steel bars with nominal diameter $\Phi 18$. Each measurement consist the average of 15 partial measurements.

Coastal areas, such as in the case of the previously referred pedestals, the constructions environment is characterized by high humidity and salt, which in combination with relatively high temperatures are favoring the chloride ions penetration in concrete. The free chloride ions in concrete consist a fixed percentage of total chloride ions (bound to concrete and free). The ratio of free $\mathrm{Cl}^{-}$to the total of the individual $\mathrm{Cl}^{-}$, varies in a range between 0.28 and 0.92 according to each situation. In cases where super-saturation of chemically bound $\mathrm{Cl}^{-}$is taking place, each addition of new $\mathrm{Cl}^{-}$increases the percentage of free $\mathrm{Cl}^{-}$in the solution, situation which is related to the corruption of steel constructions.

\section{Experimental Procedure}

\section{Induced corrosion}

For further testing of mechanical behavior and for extensive examination of the phenomena, an experimental simulation was performed on the existing protruding steel bars. This was the reason for the examination of a dual-phase, high strength steel, appearing ductility B500C, with the configuration of 10 rebar of $12 \mathrm{~mm}$ in diameter, which would consist tensile testing samples and would directly get exposed to a chloride rich environment as well. The same procedure was followed for 18 semi-embedded rebar in prismatic shape concrete $(32 \mathrm{~mm} \times 32$ $\mathrm{mm}$ ) too. For each bar, were recorded before testing its total length and mass. Prior to tensile testing, the specimens were separated into three different groups $(\mathrm{a}, \mathrm{b}, \mathrm{c})$ and were inserted in a laboratory saltspray exposure chamber, in accordance to the ASTM B117-94 [12] specification (directly exposed to the corrosive medium), for a period of 30,60 and 90 days respectively, subsistent to 8 cycles wet/dry per day.

The ASTM B117 [12] specification covers every aspect of the apparatus configuration, procedure and conditions required to create and maintain a salt spray (fog) testing environment. The selection of such a procedure for corroding the specimens, relies on the fact that the salt spray environment lies qualitatively closer to the natural 
coastal (rich in chlorides) conditions than any other accelerated laboratory corrosion test. In principle, the testing apparatus consists of a closed chamber in which a salted solution atomized by means of a nozzle, produces a corrosive environment of dense saline fog. In this particular study a special apparatus, model SF 450 (made by Cand W. Specialist Equipment Ltd.) was used. The salt solution was prepared by dissolving 5 parts by mass of sodium chloride $(\mathrm{NaCl})$ into 95 parts of distilled water ( $\mathrm{pH}$ range 6.5-7.2). The temperature inside the salt spray chamber was maintained at $35^{\circ} \mathrm{C}(+1.1-1.7)^{\circ} \mathrm{C}$.

As far as the semi-embedded in concrete steel bars are concerned, prismatic wooden tubes were used as concrete molds, with dimensions $32 \times 32 \times 500(\mathrm{~mm})$. The steel bars were placed in the molds prior to concrete casting and were held in position using specific grips. A CEM IV (according to EN-197 [13] ) cement type and crushed sand (and other fine aggregate) were used in the cement mix giving a water/ cement $(\mathrm{W} / \mathrm{C})$ and aggregate/cement $(\mathrm{A} / \mathrm{C})$ ratios of 0.66 and 3.8 , respectively.

The tubes were filled with concrete and vibrated for $20 \mathrm{~s}$ on a vibration table. After $24 \mathrm{~h}$ the molds were stripped and the concrete/ steel specimens were washed with fresh water. Following this initial curing period, 18 specimens were placed in the laboratory salt spray exposure chamber, divided into three groups. The groups of specimens remained into the chamber for 30,60 and 90 days respectively. In Figure 3 is presented a group of specimens after the corrosion process. It should be noted that since the primary aim of this particular study is to evaluate (and correlate) the nature of the corrosion damage on bare and on semi-embedded steel bars, time of exposure is not a factor of comparison. Given the fact that the corrosion rate in concrete is much slower than when the bars are directly exposed to the corrosive medium, corresponding conclusions were expected. By the end of the exposure time the surrounding concrete was crushed and the corroded steel bars were removed for tensile testing. The next step was tensile testing which took place at different time intervals. At each testing date specimens were removed from the salt spray chamber, washed with clean running water to remove any salt deposits from their surfaces and air dried. The corrosion products were removed from the surface of the specimen by means of a brittle brush, according to ASTM G1 specification [11]. The specimens were then weighed and the mass loss due to corrosion exposure was calculated as:

$$
\mathrm{X} p=\frac{m_{o}-m_{c}}{m_{o}} * 100 \%
$$

where $m_{0}$ is the mass of un corroded specimens and $m_{\mathrm{c}}$ the reduced mass of the corroded specimen.

The tensile tests were performed according to the ISO/FDIS 15630-

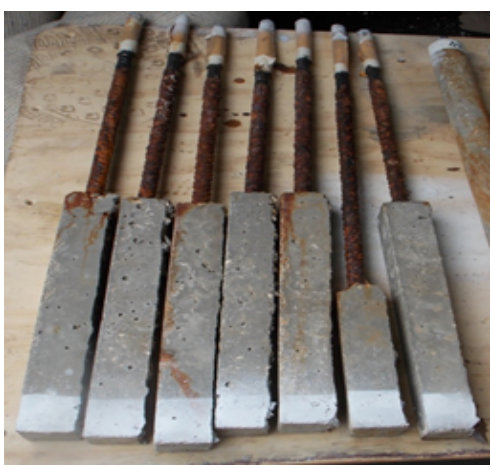

Figure 3: View of corroded rebars.

\begin{tabular}{|c|c|c|}
\hline $\begin{array}{c}\mathbf{- 5 0} \mathbf{~ m m} \\
\text { (from the surface) }\end{array}$ & $\begin{array}{c}\mathbf{0} \mathbf{~} \mathbf{m m} \\
\text { (on the surface) }\end{array}$ & $\begin{array}{c}\mathbf{+ 5 0} \mathbf{~} \mathbf{m m} \text { (from the } \\
\text { surface) }\end{array}$ \\
\hline 17.55 & 16.25 & 16.72 \\
\hline 17.48 & 16.34 & 16.79 \\
\hline 17.42 & 16.43 & 17.05 \\
\hline 17.33 & 16.47 & 16.88 \\
\hline 17.26 & 16.31 & 16.94 \\
\hline
\end{tabular}

Table 3: Results of diameter measurements $(\mathrm{mm})$ on the protruding area region $B$.

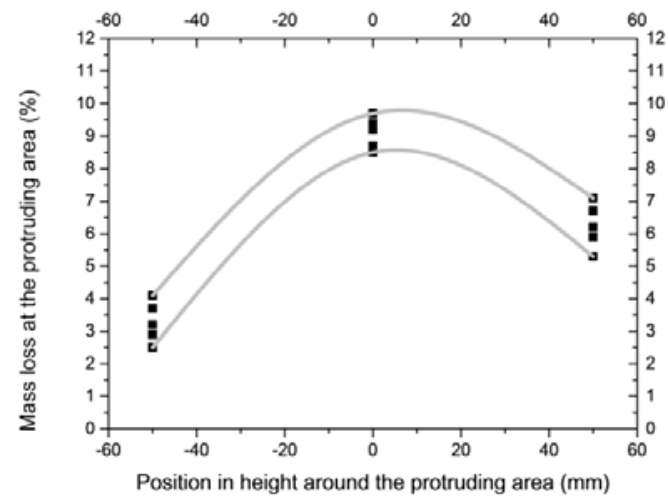

Figure 4: The mass loss at the protruding area of the steel bars.

1 [14] specification, using a servo-hydraulic MTS 250KN machine with a constant elongation rate of $2 \mathrm{~mm} / \mathrm{min}$. The mechanical properties, yield strength $R_{\mathrm{p}}$, ultimate strength $R_{\mathrm{m}}$, and uniform elongation $A_{\mathrm{gt}}$ ' were determined. It should be noted that $A_{\mathrm{gt}}$ was measured according to the manual method described in the relevant standard (on a gauge length of $100 \mathrm{~mm}$, at a distance of $50 \mathrm{~mm}$ away from the fracture).

According to ELOT 1421-1 [15] the chemical composition of B500c steel in maximum by weight permissible values is $C=0.24, S=0.055$, $\mathrm{P}=0.055, \mathrm{~N}=0.014$, and $\mathrm{Cu}=0.85$ and the equivalent carbon content Ceq was determined to be 0.52 . The material yield stress is $\geq 500(\mathrm{MPa})$, the ratio $1.15 \leq \mathrm{Rm} / \mathrm{Ry} \leq 1.35$ and elongation at maximum load $\geq 7.5 \%$.

\section{Results and Discussion}

\section{Mass loss}

As shown in Table 3 the mean diameter of the protruding bars of the pedestals, after a period of about 2 years of exposure to the natural environment (exposure class $\mathrm{XS}_{2}, \mathrm{XS}_{3}$ according to EN 206 [2]) is proved to be impaired in three discrete positions in height of the bars. In the free (bare) sections of the bars (region A), the percentage drop is 2.5-4.1\%, at the protruding area (region B) the percentage drop is 8.5 $9.7 \%$ and in depth of $50 \mathrm{~mm}$ from the protruding area the percentage drop is about $5.2-7.1 \%$.

Based on the results of the average diameter measurements (Table 3 ) in reference to their position in height around the protruding area of the bars, the sectional loss/mass loss was calculated and is depicted in Figure 4. These measurements showed a significant cross sectional reduction of the protruding steel bars in the short duration of two years, which directly raises structural integrity issues concerning constructions of high importance, just like the bridge's pedestals.

To control the degradation of semi -embedded steel bars after the laboratory corrosion, mass loss was measured for both groups of rebar 
(group A-bare, group B-semi embedded). After cleaning, according to ASTM G1 specification [11] and weighting, the percentage mass loss was calculated. Table 3 presents the results of mass loss for the two rebar groups (bare and embedded).

As far as the damage extension that the rebar were sustained is concerned, attention should be paid to the following: The embedded part of the rebar remained almost unaffected in all exposure times, in contrast to the bare part where the damage recorded was visible and obvious, since it functioned as a sacrificial anode (Figure 5). Due to this fact, the calculation of rebar mass loss of group B was performed with reference to the length of the exposed part which suffered (failed) corrosion damage.

Comparing the corrosion damage of the bare and the semiembedded specimens, it is obvious that at the early stages of group's A corrosion test, have been recorded quite high mass losses, which over exposure time (for 90 days) have balanced by the corresponding group B. A reference to these data is made on Table 3 and Figures 6 and 7.

\section{Mechanical properties}

Corrosive effects of chloride ions on reinforcement rebar, lead to local reduction of the cross sectional area and as a result to steel bar's mechanical properties reduction. Figure 8 is related to these conclusions, where are given indicative diagrams for a reference specimen and for the corroded specimens $1 \mathrm{a}, 4 \mathrm{~b}$ and $5 \mathrm{c}$ of group $\mathrm{B}$. From the results of Table 3, a notable percentage drop was recorded in strength properties (Rp, Rm), since it is almost two times the respective mass loss. As a result, yield strength (Rp) drop is $6.22 \%, 13 \%$ and $21.7 \%$ for mass loss about $3.43 \%, 6.29 \%$ and $11.08 \%$ respectively. On the contrary, on bare specimen cannot confirmed the same behavior as the percentage drop of yield strength $(\mathrm{Rp})$ is $9.76 \%, 1.63 \%$ and $19.26 \%$ which are corresponding to an overrun of about $1.50 \%, 6.70$ and $9.47 \%$ mass loss respectively. Mass loss for group B samples around 6.29\%,

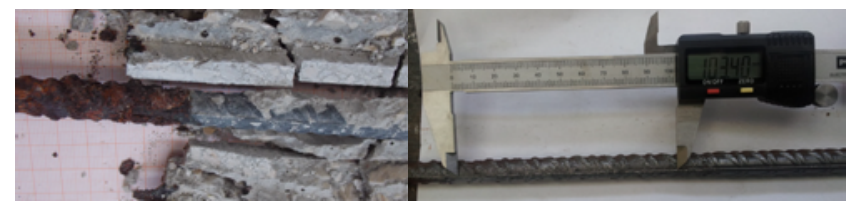

Figure 5: View of the protruding area of a specimen (left),view of the bare area of a specimen (right).

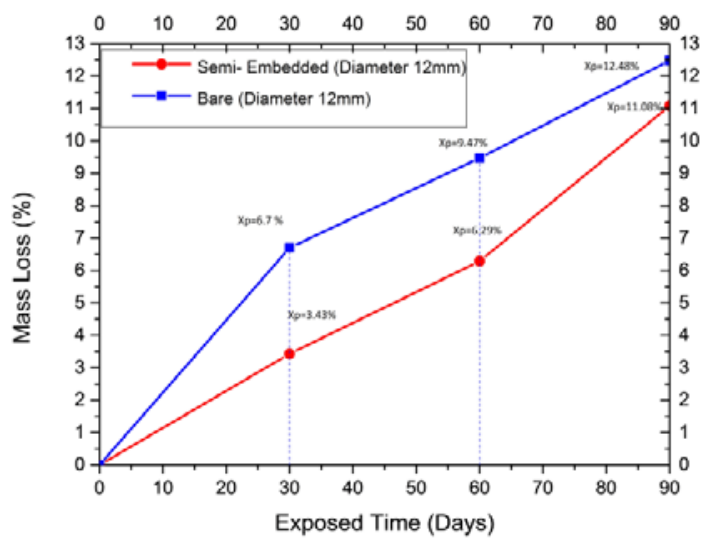

Figure 6: The mass loss rate of the bare and the semi-embedded specimens.

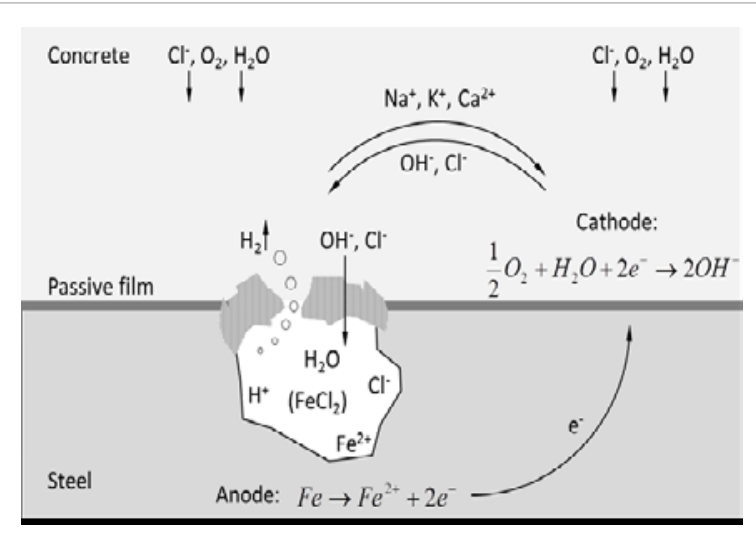

Figure 7: Schematic representation of chloride induced pitting corrosion [22]

gave values of yield strength (Rp) under the threshold of $500 \mathrm{MPa}$ which is defined by $\mathrm{EC}_{2}$ for class $\mathrm{c}$ steels. The fact that mechanical behavior of group B was worse than that of group A, can be partly explained by the local noticeable reduction of the sectional area, at protruding height. In fact, the findings concerning corrosion damage of naturally corroded steel bridge pedestals, were confirmed and are shown in Figure 4 . The surface cracking due to corrosion of RC structures has been investigated by other researchers [16-21]. When the production of rust begins, it gradually builds pressure around the reinforcing steel. In this case, at the emergence height of protruding steel bars, this buildup of pressure eventually cracks the concrete around the steel, and the crack or cracks propagate with further increase of pressure. The consequence of this fact is the surface propagation of cracks and the spalling or breaking off initiation of the adjacent concrete. This is the point where free chloride ions penetration begins. At the same time begins an interaction with concrete's $\mathrm{Ca}(\mathrm{OH})_{2}$, which not only results in $\mathrm{CaCl}_{2}$ production (which is more aggressive than $\mathrm{NaCl}$ ), but also these compounds are in constant touch with the steel bar surface. Such a phenomenon, has as a result a high local steel bar damage, which is disproportionate to the bare part. Also, the presence of elemental sulfur (coming from atmospheric deposits) in a wet sour line can cause very severe localized corrosion of the steel in the sulfur particles come in contact with the steel. Although there is a number of papers in the literature discussing this phenomenon, at these areas can get formed a variety of $\mathrm{FeS}, \mathrm{FeS}_{2}$ and $\mathrm{MnS}$ corrosion products.

The local macroscopic damage of the bar is always accompanied by pitting corrosion. The pitting can be displayed under various mechanisms. The mechanism of pitting corrosion of embedded steel bars is shown graphically in Figure 7 [22].

The acute local reduction of the cross sectional area of the naturally corroded protruding steel bars (Table 3) in comparison with the corresponding laboratory tests on protruding areas, consist a major problem and requires further investigation. Nevertheless, it is known that in cases where is obvious the appearance of bacteria or algae and fungi, is implied the presence of Microbiological Induced Corrosion (MIC). Generally, the degree of microbial colonization on the metallic surfaces is disparate, this aids in generating corrosion potentials as large as that generated between incompatible metals [3,4]. But given the strong local vegetation and generally the microclimate due to standing water in the area of bridge pedestals, the worst steel bar mass loss may be attributed to the coexistence with Microbiological Induced Corrosion (MIC). 
Citation: Drakakaki Arg, Diamantogiannis G, Apostolopoulos CH, Apostolopoulos Alk (2015) Mechanical Behavior of Corroded Protruding Rebars From Unfinished Concrete Structures. J Appl Mech Eng 4: 165. doi:10.4172/2168-9873.1000165

Page 5 of 6

In Figure 8 is shown the uniform elongation percentage drop, which reflects the mean value between the two distinct parts of the semi-embedded specimens, since only one of the two parts is corroded. However, the uniform elongation measurement results in each distinct part of the whole steel bar depict two completely different mechanical behaviors

A worthy of attention point in this Figure 9, is the behavior of the embedded steel bars which are exposed to salt spray environment until 60 days, which present two Ludder regions, something that implies high deformations. . It is thus a single material with two yield points. This fact introduces disfavor issues concerning the response of structural elements made of reinforced concrete. Moreover, the appearance of two Ludders regions in the $[\sigma-\varepsilon]$ diagrams of the steel protruding introduces important issues for different regulations concerning structures design. In this sense, the steel is calculated (obtained) with a maximum deformation of $0.2 \%$ in its initial state of yield point and respectively the concrete with a maximum deformation of $0.35 \%$ before the fracture. Given that a reliable estimate of any construction of reinforced concrete is subject to meeting these constraints, a question of credibility is raised at least for the "batch" of steel tested in this study.

On Table 4, is presented the mean value of the maximum plastic elongation that was measured on the bare part of the semi-embedded steel bars in reference to the corrosion level. Thus, the corresponding measurement taken from a specific part, with recorded corrosion

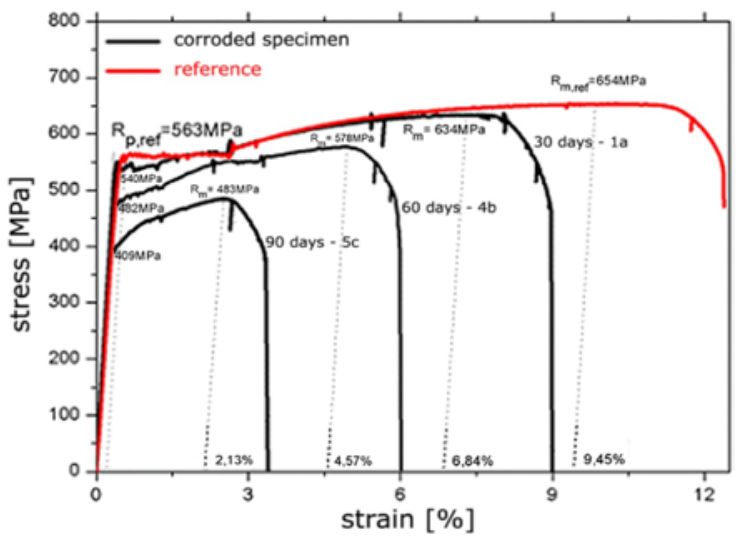

Figure 8: Tensile graphs for semi-embedded steel bars B500c.

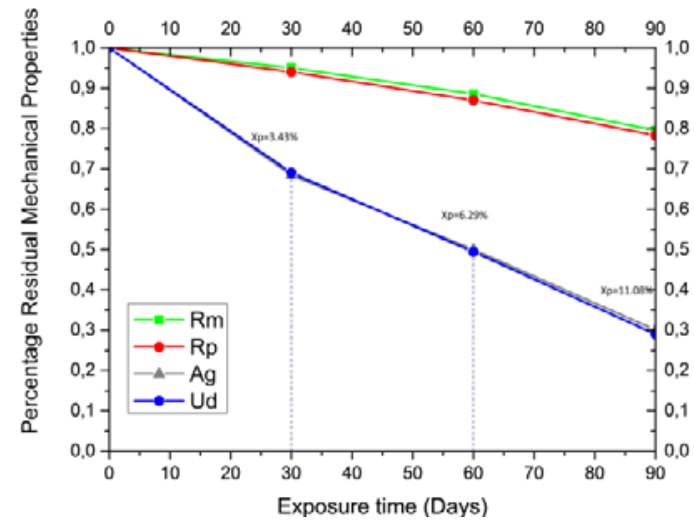

Figure 9: Percentage residual mechanical properties in reference to the percentage mass loss for semi-embedded steel bars.

\begin{tabular}{|l|c|c|c|c|c|c|}
\hline Rebar type & $\begin{array}{c}\text { Days in } \\
\text { salt spray } \\
\text { chamber }\end{array}$ & $\begin{array}{c}\text { Mass } \\
\text { Loss } \\
(\%)\end{array}$ & $\begin{array}{c}\text { Ultimate } \\
\text { Strength } \\
\text { Rm (MPa) }\end{array}$ & $\begin{array}{c}\text { Yield } \\
\text { Strength } \\
\text { Rp (MPa) }\end{array}$ & $\begin{array}{c}\text { Uniform } \\
\text { Elongation }\end{array}$ & $\begin{array}{c}\text { Energy } \\
\text { Density }\end{array}$ \\
\hline B500c & 0 & 0 & 654.13 & 561.43 & 9.36 & U (MPa) \\
\hline Bare & 0 & 0 & 654 & 562 & 9.3 & 54.84 \\
\hline Semi-embedded & 30 & 6.69 & 595.62 & 506.61 & 7.14 & 38.65 \\
\hline Bare & 30 & 3.43 & 622 & 527 & 6.36 & 37.91 \\
\hline Semi-embedded & 60 & 9.47 & 572.78 & 490.53 & 6.08 & 34.17 \\
\hline Bare & 60 & 6.29 & 580 & 489 & 4.67 & 27.08 \\
\hline Semi-embedded & 60 & 12.48 & 530.99 & 453.29 & 4.85 & 25,17 \\
\hline Bare & 90 & 11.08 & 520 & 440 & 2.78 & 15.65 \\
\hline Semi-embedded & 90 & & & & & \\
\hline
\end{tabular}

Table 4: Average mechanical properties for bare and semi-embedded steel bars in corrosive environment for different exposure times.

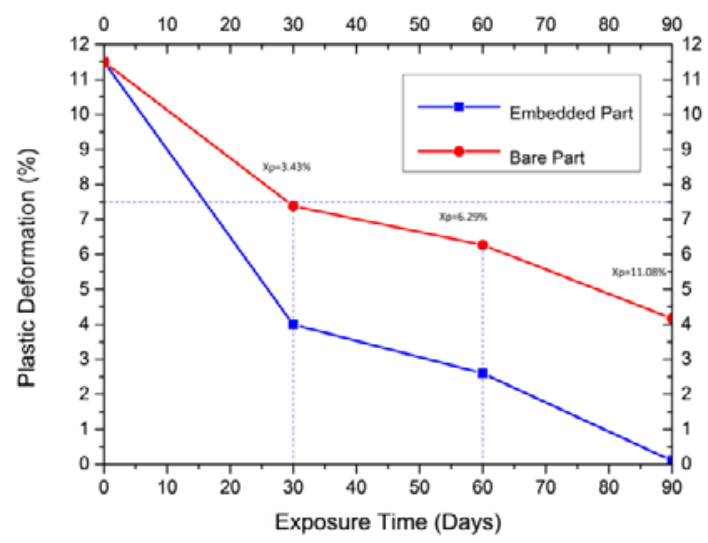

Figure 10: The plastic deformation undertaken by each part of the semi embedded steel bars according to the corrosion level.

about $3.43 \%$, noted maximum plastic elongation $7.38 \%$, while the noncorroded part noted $3.99 \%$ maximum plastic elongation. Respectively, for mass loss $6.29 \%$, the max plastic elongation which was recorded was $6.27 \%$ and for the non-corroded part $2.60 \%$. At the same time, for mass loss about $11.08 \%$, the maximum plastic elongation which was taken was $4.17 \%$ while the non-corroded part had not received any plastic deformation (Figure 10). For mass loss 3.43\%, 6.29\%, 11.08\%, the percentage drop of maximum plastic elongation was found to be $21.23 \%, 33.16 \%$ and $55.54 \%$ respectively.

In any case, the values of uniform elongation are found to be quite low in comparison with the threshold set by EC2 for high ductility steels class c, which is defined about $7.50 \%$.

From both Table 4 and Figures 6-8 it is obvious that the corrosive agent, for both groups A and B, is time dependent and has a direct impact on the steel mechanical properties.

Tensile testing of these samples gave a series of strength and ductility properties. However, the observed local discontinuities in the stress-strain curves of the corroded semi- embedded steel bars can be attached to any local detachments in the interface of martensite and transition zone. Related to this point, is the ApostolopoulosDiamantogiannis JAME [23] manuscript which refers to the same dual-phase steel B500c. Also, the existence of internal micro voids, which were formed near the fracture surfaces, in combination with surface pits (because of chloride ions) may be responsible for their fast 
Citation: Drakakaki Arg, Diamantogiannis G, Apostolopoulos CH, Apostolopoulos Alk (2015) Mechanical Behavior of Corroded Protruding Rebars From Unfinished Concrete Structures. J Appl Mech Eng 4: 165. doi:10.4172/2168-9873.1000165

Page 6 of 6

coalescence and the specimens' failure at low deformation values.

In Figure 9 is depicted the dramatic drop of semi-embedded steel bar ductility properties in reference to the percentage mass loss. In all cases, with the increase of the corrosion exposure time, a continuous almost linear decrease in the yield and tensile strength and the uniform elongation was observed. The mass loss of corroded reinforcing steel bars is directly related with their mechanical strength properties. Additionally, the fact that the corrosion level had a great impact on the degradation rate of mechanical properties was expected since the pits and notches, which were generated due to corrosion, are especially high and determinative for the creation of stress concentration points (Figure 10).

Although it is widely known that chloride induced reinforcement corrosion is one type of highly localized (pitting) corrosion and corrosion experiments of steel embedded in concrete often aim at determining the chloride threshold values $\left(\mathrm{C}_{\mathrm{th}}\right)$, in this case of protruding steel bars the damage mechanism in emergence area is obviously different. Moreover, the protruding corrosion damage focuses on a small area of the bar, which should arise reflection and concern as these areas may have unpredictable and unfavorable behavior in case of strong seismic events.

This investigation was carried out to determine the influences of the reinforcement corrosion level on the mechanical behavior of steels and in particular the effect of corrosion on existing protruding steel bars. Investigation results may help field engineers in making decisions concerning the use of corroded bars in construction. Accordingly, in order for the conclusions of the present study to get used for the seismic analysis of RC structures suffering from corrosion of reinforcement we need to understand how corrosion of reinforcement changes the constitutive behavior of reinforcing steel under monotonic and cyclic loading.

\section{Conclusions}

The following conclusions can be drawn from the present study:

- Mass loss measurements were taken from protruding area of B500c dual phase rebar after natural and laboratory accelerated corrosion due to chloride ions.

- Combination of ex situ characterization and in situ locally probing is very powerful for the study of localized corrosion of the reinforcement steel.

- The mechanical behavior (tensile tests) study of both laboratories corroded bare and semi-embedded steel bars was useful for a further understanding of the localized corrosion behavior of protruding rebar.

- Protruding steel bars with an average mass loss at about $4 \%$ of a reference bar showed Yield strength and Uniform Elongation below the limits that are set by the EC2 for high ductility steels.

As it was proved by the comparison of the mass loss results of the bare and the semi-embedded specimens, the corrosion mechanism differs for the two categories. The confirmation is given by tensile tests diagrams $[\sigma-\varepsilon]$ which depict the appearance of two Ludders areas on semi-embedded steel bars, something that needs further investigation.

\section{References}

1. ISO 12944: International standard for paints and varnishes. Corrosion protection of steel structures by protective paint systems.
2. EN 206-1: Concrete, Part 1: Specification, performance production and conformity

3. Little B, Wagner P, Mansfeld M (1991) Microbiologically influenced corrosion of metals and alloys. Int Mater Rev 36: 253-272.

4. Videla HA, Herrera LK (2005) Microbiologically influenced corrosion: looking to the future. Int Microbiol 8: 169-180.

5. Almusallam AA (2001) Effect of degree of corrosion on the properties of reinforcing steel bars. Construc. Build Mater 15: 361-8.

6. Apostolopoulos Ch Alk, Apostolopoulos (2009) The influence of corrosion and Cross-Section Diameter on the Mechanical Properties of B500c steel, Journal of Materials Engineering and Performance 18: 190-195.

7. Apostolopoulos $\mathrm{CH}$, Kappatos V (2013) Tensile properties of corroded embedded Steel Bars B500c in concrete. International Journal of Structural Integrity 4: 275-294.

8. Kappatos V, Apostolopoulos CH (2013) Tensile Mechanical properties of Reinforced Steel Bars B500c in coastal structures. Journal in Materials Evaluation 71

9. Papadakis VG, Fardis MN, Vayenas CG (1996) Physicochemical processe and mathematical modeling of concrete chlorination, Chemical Engineering Science 51: 505-513.

10. Chung- Ho H (2014) Effects of Rust and Scale of Reinforcing Bars on the Bond Performance of Reinforcement Concrete, Journal of Materials in Civil Engineering 26: 576-584.

11. ASTM Standard G (2011) Standard practice for preparing, cleaning and evaluating corrosion test specimens ASTM International.

12. ASTM Standard B 117: Standard practice for operating salt (fog) testing apparatus.

13. EN 197 (2000) European Standard, Cement, Composition, specifications and conformity criteria for common cements.

14. UNI EN ISO 15630-1:2010, Steel for the reinforcement and pre-stressing of concrete. Test methods. Part 1: Reinforced bars, wire rod and wire. Eur. Com Stand.

15. ELOT 1421-1: Hellenic Standard (Draft), Steel for the reinforcing of concrete. Weldable Reinforcing steel

16. Vidal T, Castel A, Francois R (2004) Analyzing crack width to predict corrosion in reinforced concrete. Cement and Concrete Research 34: 165-174.

17. Arya C, Ofori-Darko FK (1996) Influence of crack frequency on reinforcement corrosion in concrete. Cement and concrete composites 26: 345-353.

18. Maaddawy ET, Soudki K, Topper T (2005) Long-term Performance of Corrosion- Damaged Reinforced Concrete Beams. ACI Structural Journal 102 649

19. Mohammed TU (2001) Effect of Crack Width and Bar Types on Corrosion of Steel in Concrete. Journal of Materials in Civil Engineering 13: 194-201.

20. Francois R, Arliguie G (1999) Effect of micro cracking and cracking on the development 72 of corrosion in reinforced concrete members. Magazine of Concrete Research 51: 143-150.

21. Schiebl P, Raupach M (1997) Laboratory studies and calculations on the influence of crack width on chloride-induced corrosion of steel in concrete. AC Materials Journal 94: 56-62.

22. Nelson S (2013) Chloride induced Corrosion of Reinforcement Steel in Concrete. Threshold values and Ion Distributions at the Concrete-Steel Interface, Thesis for the Degree Of Doctor of Philosophy, Department of Civil and Environmenta Engineering, Chalmers University of Technology, Gothenburg, Sweden.

23. Apostolopoulos CH, Diamantogiannis G (2012) Structural Integrity Problems in Dual-Phase High Ductility Steel Bar. Journal of Applied Mechanical Engineering 1(5). 